\title{
Radial neck fracture reduction and fixation by titanium elastic nail (Metaizeau): A method used in adults too
}

\author{
Pathik Vala $^{1, *}$, Shreyas Gandhi ${ }^{2}$, Abhijeet Salunke ${ }^{3}$, Ajay Devda ${ }^{4}$, Rutvik Shah $^{5}$ \\ ${ }^{\mathbf{1}}$ Assistant Professor, ${ }^{2}$ Professor, ${ }^{\mathbf{3}, \mathbf{4}}$ Consultant, ${ }^{5}$ Senior Resident, Dept. of Orthopaedics, ${ }^{1,5}$ AMC MET College \& LG Hospital, \\ Ahmedabad, Gujarat, ${ }^{2}$ C. U. Shah Medical College and Hospital, Surendranagar, Gujarat, ${ }^{3}$ Gujarat Cancer Research Institute, \\ Ahmedabad, Gujarat, ${ }^{4}$ Devda Orthopedic Trauma \& Joint Replacement Hospital, Palanpur, Gujarat, India
}

*Corresponding Author:

Email: pathikvala88@gmail.com

\begin{abstract}
Radial neck fractures comprises of less than $1 \%$ of all fractures in adults. They are more common in children than adults. Majority of cases require surgical management especially in adults. Surgically preferred management comprises of closed/open reduction and internal fixation using various types of plates/wires. We have performed Metaizeau technique in seven adults with successful treatment and functional outcome. This technique is very well described in children.
\end{abstract}

\section{Background}

In adults, isolated radial neck fractures are very rare with incidence of $1 \%$ of all fractures. ${ }^{2}$ The prognosis depends upon the degree of displacement, the age of the patient, associated elbow injury and the method the treatment. Less than 30 degree of angulation is generally acceptable. ${ }^{1}$ Restoration of radial neck angulation and displacement is essential to restore the normal biomechanics and stability of the elbow. Open reduction and internal fixation (ORIF) is associated with non-union, implant related complications, reduced range of motion, heterotrophic bone formation and avascular necrosis of the radial head. The standard procedure accepted for isolated radial neck in pediatric age group is centromedullary pinning (Metaizeau technique).

\section{Methodology \\ Between January 2016-January 2017, 7 patients were operated with TENS(Metaizeau technique).Chosen patients were diagnosed with isolated radial neck fractures without elbow joint instability. Fracture morphology in all the patients had angulation more than 30 degrees and were displaced. All the patients had type 3 fracture according to Mason's classification and type 2 or 3 according to Judet classification. The mean age of the patients was 32 years old and all were operated with 7 days of suffering the injury. The mean followup was for the duration of 9 months.}
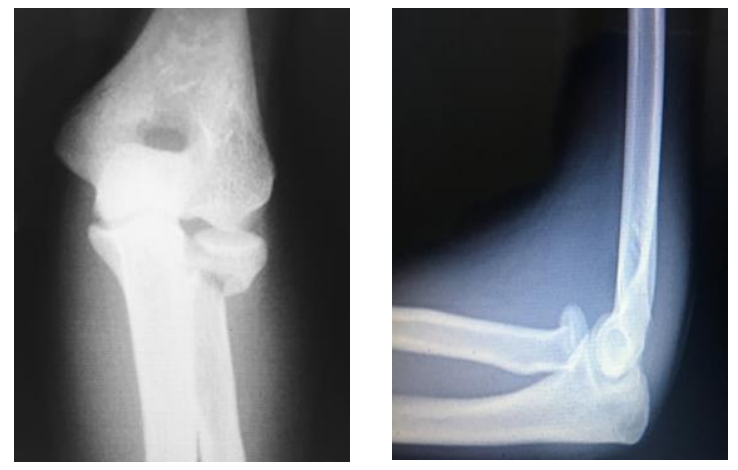

Fig. 1: Anterior posterior and lateral view of radial head fracture

\section{Surgical Technique}

Patient was taken in Operating Rooms after the adequate preop fitness being obtained.Supine position was given to the patient. Axillary/Supraclavicular block was opted for. Hand rest was attached to the side of the operating table. The IITV(Image intensifier television) view was taken to confirm the fracture position. The surgeries performed was described by Metaizeau, using intramedullary nailing in form of TENS. Painting and draping of to be operated upper limb was done. The corticocancellous and metaphyseal junction of the radial styloid process was marked under image intensifier. This was served as the entry point for TEN.TEN of appropriate length and thickness was selected by keeping it on the forearm and estimating on IITV. Radial styloid was taken as an anatomical landmark and $1 \mathrm{~cm}$ incision was made and superficial branch of radial nerve was dissected and retracted .The lateral radial cortex was exposed and entry was made with the help of entry awl. Prebending of TEN was done before the introduction of the nail to accumulate it inside the curved radial diaphysis. TEN was introduced into the corticocancellous to metaphyseal to diaphyseal zone and to the radial head. With the help of gentle corkscrew movements the TEN was advanced and also 
after it reach the proximal radius a gentle reduction with the tip of the TEN was done under fluoroscopic control. The confirmation was done under AP and Lateral views of IITV. The appropriate length was estimated and nail was cut flush to the styloid process protecting the skin and surrounding soft tissue. According to the width of the intramedullary canal, one TEN with measured thicknesses was used for closed intramedullary pinning in all patients. All the surgeries were done on the $3^{\text {rd }}$ or $4^{\text {th }}$ admitted day(average interval 1-7 days).Patients were immobilized post operatively with a Above elbow slab for 2 days for pain relief and subsidence of swelling. Regular dressings were performed on $2^{\text {nd }}$ and $4^{\text {th }}$ postoperative day. The check X-ray was performed at 1 week. Mobilization was started after the check x-rays of 4 weeks. Nail was removed after the union was achieved.

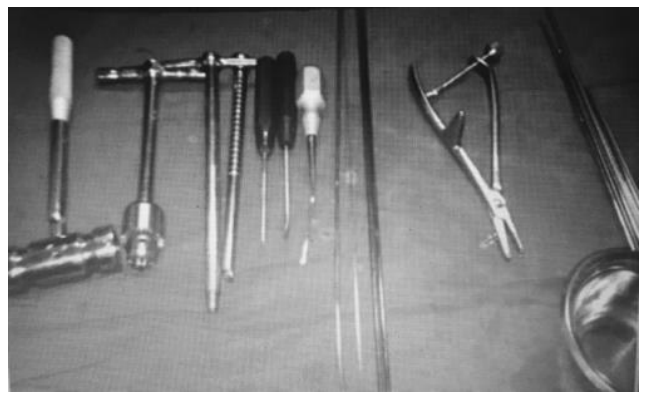

Fig. 2: Instruments used for the technique

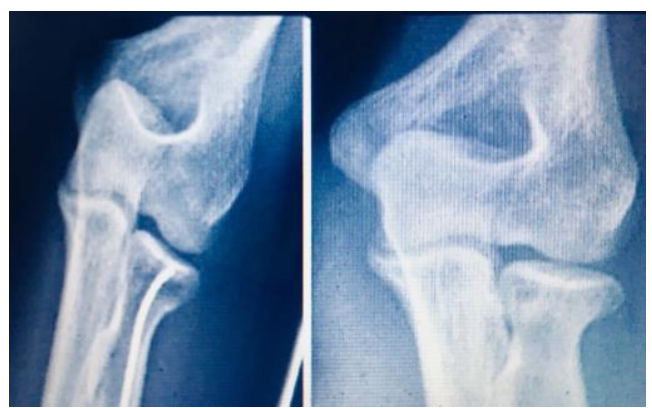

Fig. 3: Postoperative Xray and Xray after removal of implant
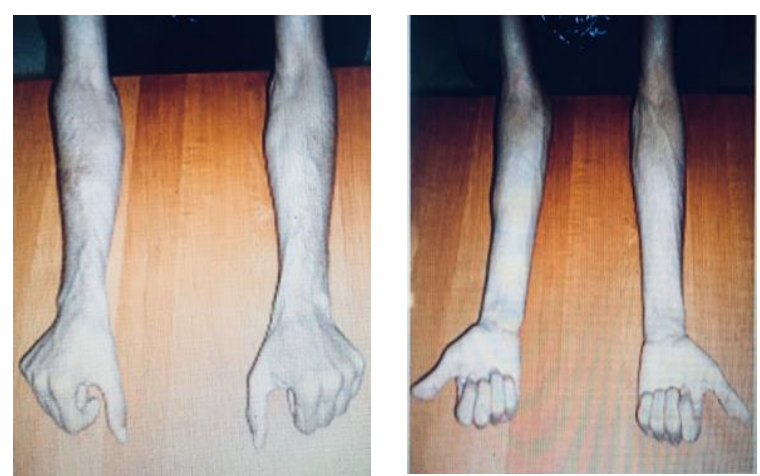

Fig. 4: Range of Movements after operative intervention

\section{Management}

Radial head fixation was managed initially with the above elbow slab given for initial pain relief and swelling reduction. There are options for conservative versus surgical management. Considering the conservative management opting would result into complications like malunion, cubitus valgus and secondary displacement. Surgical options includes open reduction and plating/ K-wiring which itself carries its own set of complications like non union, heterotrophic bone formation, implant related complications and avascular necrosis of radial head.
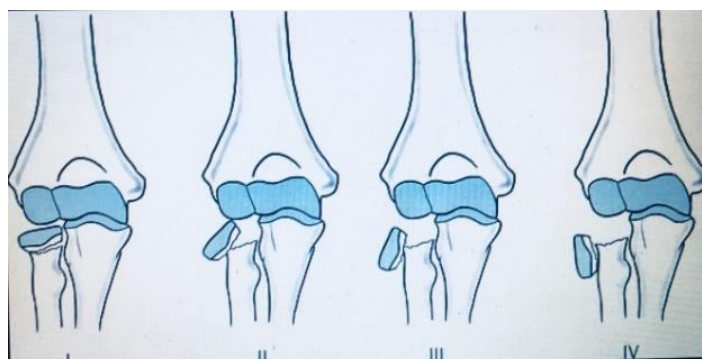

Fig. 5: Judet classification, type1-undisplaced, type 2-<30 degree angulation, type 3-30 to 60 degrees angulation, type 4-60 to 90 degrees of angulation

\section{Discussion}

Radial head and neck fractures occur as a result of two different but most commonly they result from a fall onto an outstretched hand with the elbow in extension and valgus. ${ }^{3}$

Mason Classification (Modified by Hotchkiss and Broberg-Morrey)

\begin{tabular}{|c|l|}
\hline Type I & $\begin{array}{l}\text { Nondisplaced or minimally displaced } \\
(<2 \mathrm{~mm}), \text { no mechanical block to rotation }\end{array}$ \\
\hline Type II & $\begin{array}{l}\text { Displaced }>2 \mathrm{~mm} \text { or angulated, possible } \\
\text { mechanical block to forearm rotation }\end{array}$ \\
\hline Type III & $\begin{array}{l}\text { Comminuted and displaced, mechanical } \\
\text { block to motion }\end{array}$ \\
\hline Type IV & $\begin{array}{l}\text { Radial head fracture with associated } \\
\text { elbow dislocation }\end{array}$ \\
\hline
\end{tabular}

Many research articles have shown that the outcomes of closed reduction and intramedullary pinning of isolated radial neck fractures is a fruitful and defined technique for adults too.

Current results ranging from good to best without affecting daily active life of the operated patient support the statement that this method can also be an alternative surgical procedure in the treatment of displaced radial neck fractures in adults. The pros of this method outweighs some of the cons of the method in the aspects of implant related complains like loosening of implant, screw dislocation, infection and nerve injury. Moreover, many times open reduction will be is associated with a higher rate of stiffness, loss of ROM, infection and avascular necrosis. ${ }^{3-6}$ 
Here, the choice of treatment is as close reduction and internal fixation seems to be a midway bonus options as compared to the other options of open reduction and internal fixation and conservative management. The complication ratios per se of the methods of open reduction and internal fixation can be many and also conservative treatment might lead to the osteoarthritis of the proximal radioulnar joint which can be debilitating and hampering the daily active life of the patient. Owing to the available treatment options this option of closed reduction and internal fixation with TEN seems to be a valid option to support and treat Moore's type 2-type 4 fractures as well as Judet type 2 and type 3.Moreover, the fixation of this type of fractures is to be carried out within 7 days of injury as post 1 week of injury the healing potential of the fracture starts and it would create difficulty in reduction later on during intraoperative period.

Studies reveal that pediatrics Judet type 2-type 4 fractures have been successfully treated with intramedullary TEN (Metazieau) techniques and results are promising however in adults to give a thumping note regarding the management of this fractures is considerable and required workup. Additionally, a percutaneous $\mathrm{k}$ wire can be used as an adjunct in reduction of the fracture along with the above described procedure..$^{7-10}$

Overall, this technique carries its own drawbacks. The injury to superficial radial nerve which leads to the hypoesthesia of the dorsum of the lateral aspect of the radius and also hyperesthesia of the thumb and index finger.Also chances of injury to posterior interosseous nerve is also there. Moreover, a burden of second surgery of removal of implant has also to be beared.
As of now we have used this technique only for the fractures of radial neck as sometimes it is essential to opt for ORIF for radial head fixation. On a flip note, a sort of synergistic approach can also be opted for: after open reduction of the radial head with $\mathrm{k}$ wires, the radial neck component is stabilized by use of an intramedullary pin. Additionally, ligamentous injuries and postero-lateral instabilities are also caused by fall. ${ }^{11}$ So, especially lesions of the MCL have to be excluded before the surgical procedure due to the important role of the MCL as a primary joint stabilizer in cases of radial head insufficiency.

Like any other study, this study also has its own limitations. The overall number of cases included in this study is pretty less, as such injuries are less encountered during routine practice. Also to control the radial head rotation is an uphill task in operating with intramedullary nailing. While to address rotational malalignments, it can be possible to fix the radial percutaneously by $\mathrm{k}$ wire or by manipulation.

All in all, this study has several strengths. All patients were available with a mean of 12 months of follow-up and a complete assessment of objective functional parameters and elbow scoring. Although we present some good results of the technique described by Metaziaeu, long term follow up is essential and also a study like this should be ideally done in a tertiary multicentre set up to get the best and optimum outcomes of the work being carried out.

In our study we have used metaizeau technique for the reduction of the displaced radial neck fractures and we have got optimum results in terms of pain relief, fixation and range of motion.

\section{Results}

Table 1

\begin{tabular}{|c|c|c|c|c|c|c|c|c|c|}
\hline $\begin{array}{c}\text { Sr } \\
\text { No }\end{array}$ & $\begin{array}{c}\text { Age } \\
\text { (yrs) }\end{array}$ & Sex & $\begin{array}{c}\text { Mean } \\
\text { Interval from } \\
\text { injury to } \\
\text { surgery(days) }\end{array}$ & \multicolumn{2}{|l|}{$\begin{array}{c}\text { ROM(injured upper limb after 9 } \\
\text { months post surgery) }\end{array}$} & \multicolumn{2}{l|}{ ROM(uninjured upper limb) } \\
\hline & & & & Flexion & Extension & $\begin{array}{c}\text { Pronation/ } \\
\text { Supination }\end{array}$ & Flexion & Extension & $\begin{array}{c}\text { Pronation/ } \\
\text { supination }\end{array}$ \\
\hline 1 & 30 & F & 3 & 130 & Full & $70 / 90$ & 130 & Full & $90 / 90$ \\
\hline 2 & 44 & F & 3 & 120 & Full & $80 / 80$ & 130 & Full & $100 / 90$ \\
\hline 3 & 25 & M & 2 & 130 & Full & $90 / 90$ & 140 & Full & $90 / 90$ \\
\hline 4 & 27 & M & 6 & 120 & Full & $70 / 90$ & 140 & Full & $100 / 90$ \\
\hline 5 & 34 & F & 6 & 140 & Full & $80 / 80$ & 140 & Full & $90 / 90$ \\
\hline 6 & 45 & M & 4 & 140 & Full & $70 / 90$ & 140 & Full & $90 / 90$ \\
\hline 7 & 23 & F & 3 & 130 & Full & $90 / 90$ & 140 & Full & $100 / 99$ \\
\hline
\end{tabular}

\section{Conclusions}

In the present case series, the results of the use of Metazieau technique in adults were promising. The proper selection of the patient and timings of the surgery should be considered judiciously.
Funding: No funding sources.

Conflict of interest: None declared. 


\section{References}

1. Rockwood Wilkins. Fractures in children. 7th edition. Lippincott Williams \& Wilkins. 2010.

2. Duckworth AD, Clement ND, Jenkins PJ, Aitken SA, McQueen MM. Epidemiology of radial head and neck fractures. J Hand Surg Am 2012:37(1):112-19.

3. Herring JA. Tachdjian's Pediatric Orthopaedics, 4th Edition.

4. Metaizeau JP. Reduction and osteosynthesis of radial neck fractures in children by centromedullary pinning. Injury 2005;36Suppl 1:A75.

How to cite this article: Vala P., Gandhi S., Salunke A., Devda A., Shah R.Radial neck fracture reduction and fixation by titanium elastic nail (Metaizeau): A method used in adults too. IP Int J Orthop Rheumatol 2018;4(2):57-60. 